\title{
Corrigendum
}

\section{Corrigendum to "Development of Kaolin Clay as a Cost-Effective Technology for Defluoridation of Groundwater"}

\author{
Hayat Mohammed Kebede ${ }^{1}$ and Adane Adugna Ayalew $\mathbb{1}^{2}$ \\ ${ }^{1}$ Department of Chemical Engineering, Samara University, Samara, Ethiopia \\ ${ }^{2}$ Faculty of Chemical and Food Engineering, Bahir Dar Institute of Technology, Bahir Dar University, Bahir Dar, Ethiopia \\ Correspondence should be addressed to Adane Adugna Ayalew; adaneadugna14@gmail.com \\ Received 2 February 2021; Accepted 2 February 2021; Published 22 February 2021 \\ Copyright (c) 2021 Hayat Mohammed Kebede and Adane Adugna Ayalew. This is an open access article distributed under the \\ Creative Commons Attribution License, which permits unrestricted use, distribution, and reproduction in any medium, provided \\ the original work is properly cited.
}

In the article titled "Development of Kaolin Clay as a CostEffective Technology for Defluoridation of Groundwater" [1], Dr. Hayat Mohammed Kebede was missing from the author list, who contributed to conceiving, designing, and planning the study, in addition to obtaining, analyzing, and interpreting the data. The corrected author list is shown above.

\section{References}

[1] A. A. Ayalew, "Development of Kaolin Clay as a Cost-Effective Technology for Defluoridation of Groundwater," International Journal of Chemical Engineering, vol. 2020, Article ID 8820727, 10 pages, 2020. 